\title{
A STUDY OF THE EFFECTS OF PYLORIC OBSTRUCTION IN RABBITS
}

By JAMES L. GAMBLE AND MONROE A. MCIVER

With Assistance of Pauline Marsh

(From the Laboratories of the Departments of Pediatrics and of Physiology, the Harvard Medical School, and the Medical Service of the Children's Hospital and the East Surgical Service of the Massachusetts General Hospital)

(Received for publication May 15, 1925)

\section{INTRODUCTION}

In a recent paper Gamble and Ross (1) have demonstrated that, in the presence of pyloric obstruction in the dog, there occurs a loss in vomited gastric secretions of sodium as well as of chloride ion and water. They have shown the relationship of this loss of base to changes in the chemical structure of blood plasma and its significance from the point of view of the reparative action of injections of $\mathrm{NaCl}$ solution.

In this paper are presented measurements of the amounts of water, fixed base and chloride found in the stomachs of rabbits following experimental obstruction of the pylorus. These measurements were obtained with the purpose of determining quantitatively the extent of the loss into the stomach of each of these important components of the body fluids during the survival period following pyloric obstruction. Rabbits were used for the reason that in these animals the vomiting reflex is absent. Their stomachs will therefore conveniently collect for measurement substances leaving the body in the gastric secretions and contamination of this material by urine or feces is dependably avoided. It was found, however, that the collection period following obstruction could not be begun with an empty stomach. More than a week of fasting is required to completely empty a rabbit's stomach. The usual content is of a stiff texture and attempts to either wash it out or remove it surgically without considerably traumatizing the stomach were unsuccessful. The plan used in estimating 
the loss into the stomach of water, fixed base, and chloride ion consisted in comparing measurements from control and operated animals. Fortunately the changes in the findings were of such magnitude as to render this method of approximate measurement satisfactory for the purposes of this study.

Besides these data demonstrating a rapid loss of blood plasma constituents, the results of a few analyses of muscle tissue and of skin are given which indicate a limited availability of material for correct repair of the plasma. The character of the actual resultant alteration of the acid-base composition of the blood plasma is illustrated by a few measurements of the concentrations of fixed base and of chloride and bicarbonate ions obtained from samples of blood serum.

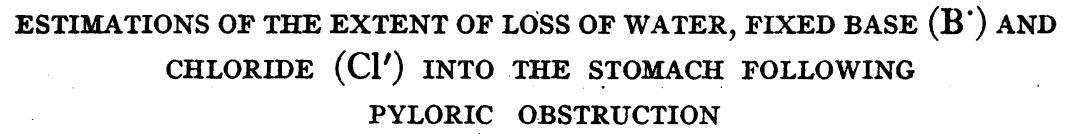

Measurements were obtained from the stomach contents of four controls (nos. 1, 2, 3 and 4) and from four rabbits following obstruction of the pylorus (nos. 5, 6, 7 and 8). The obstruction was produced by ligaturing the duodenum just below the pylorus with tape, the operation being carried out and the abdominal wound closed with aseptic precautions under ether anesthesia. In an additional experiment (rabbit 9) the obstruction was placed $40 \mathrm{~cm}$. below the pylorus, i.e., presumably at or somewhat beyond the lower end of the duodenum. The animals, except nos. 8 and 9 which were found dead, were killed with ether; the operated ones as near the end of the survival period as could be judged. Two other rabbits (nos. 10 and 11) were given intraperitoneal and subcutaneous injections of 0.9 per cent $\mathrm{NaCl}$ solution. Rabbit 10 received $250 \mathrm{cc}$. intraperitoneally and $150 \mathrm{cc}$. subcutaneously 24 hours and 29 hours respectively following operation. Rabbit 11 was given three intraperitoneal injections of $140 \mathrm{cc}$. each, $\frac{1}{2}, 18$ and 25 hours after placing the obstruction. The former was killed with ether when obviously moribund and the latter while still alert and vigorous. The animals were placed in metabolism cages after operation. Food and water were withheld. The two that were given injections of $\mathrm{NaCl}$ solution voided small amounts of urine, the others were almost, or entirely, anuric. The rabbits did not 
JAMES L. GAMBLE AND MONROE A. MCIVER

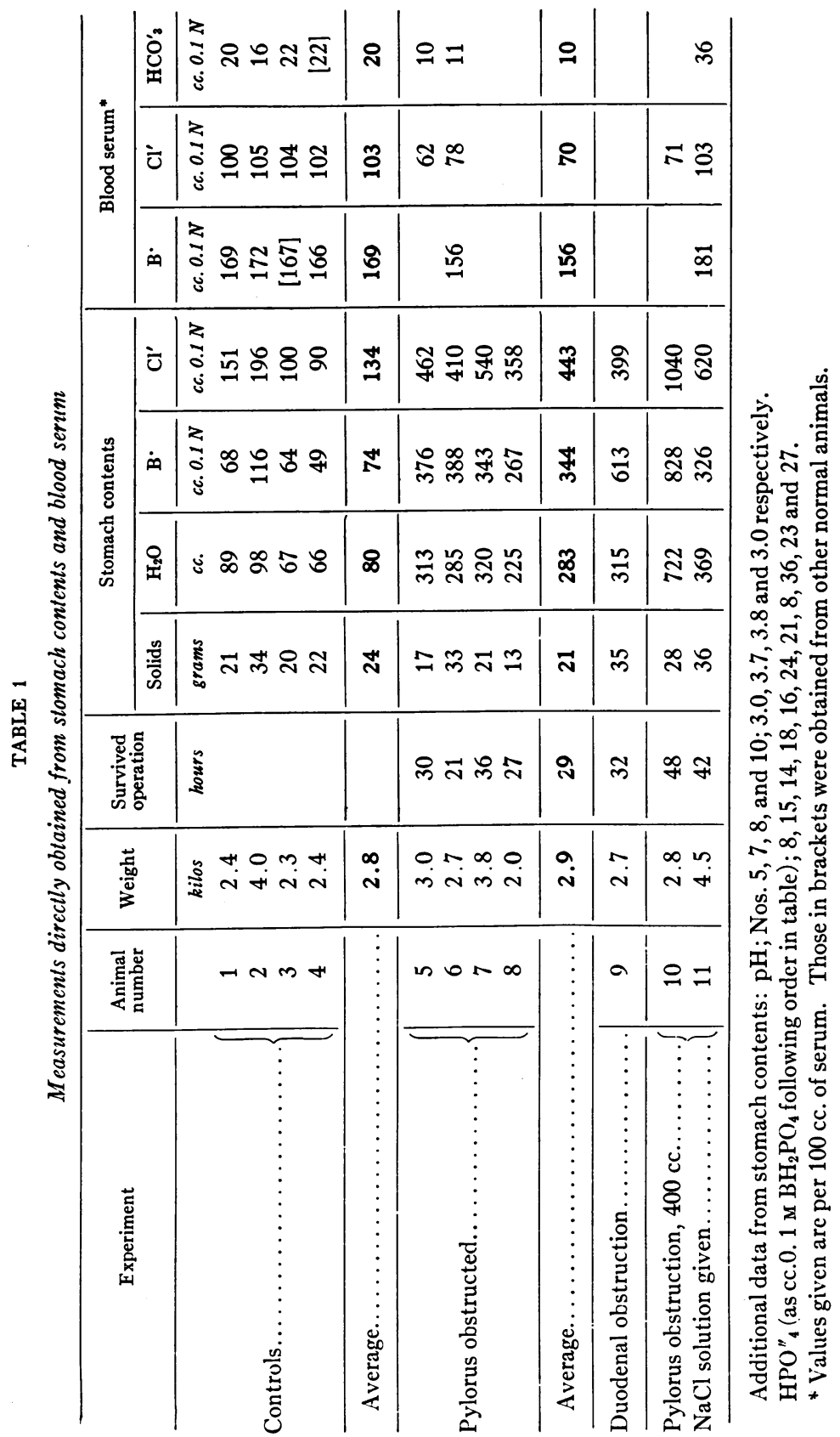


vomit. It was planned to obtain a single blood sample from each of the animals but unfortunately, in the case of the operated animals, successful collection of a sufficient amount of blood for the three desired measurements near the end of the survival period was accomplished in only two instances.

The data obtained are given in table 1. It will be noted that the animals differed considerably in weight. The average weight of the

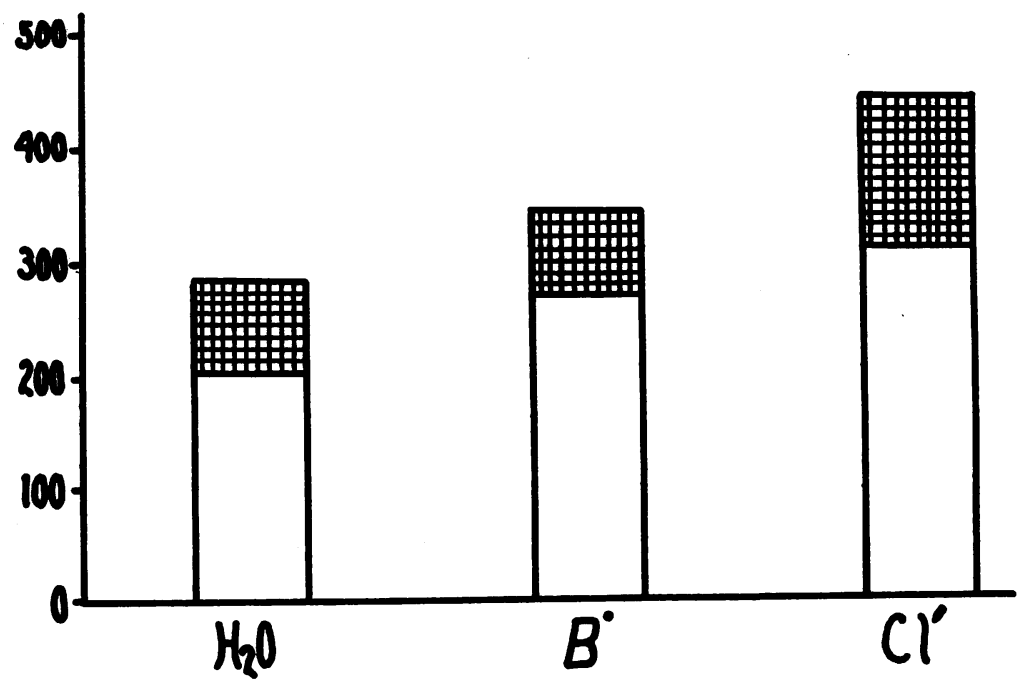

Fig. 1. Averages of Measurements of $\mathrm{H}_{2} \mathrm{O}$, B and $\mathrm{Cl}^{\prime}$ from Stomach Con-tents of Controls Laid Off (Cross-hatched Portion of the DiaGRAMS) ON ThOSE From RabBits With ObStruction of THE Pylorus to Indicate Extent of Losses into Stomach Following Obstruction

Measurements of water given in cubic centimeters and those of $\mathrm{B}^{\prime}$ and $\mathrm{Cl}^{\prime}$ as $\mathrm{cc}$. of tenth normal solutions. Data from table 1.

controls and of the four animals with obstruction placed at the pylorus was, however, almost the same. The averages of the measurements from these two groups demonstrate clearly that large amounts of $\mathrm{H}_{2} \mathrm{O}, \mathrm{B}^{\prime}$, and $\mathrm{Cl}^{\prime}$ enter the stomach following pyloric obstruction. The extent of these losses is represented graphically by means of the diagrams in figure 1.

In table 2 are given the results of estimations of the extent of with- 
drawal of $\mathrm{H}_{2} \mathrm{O}, \mathrm{B}^{*}, \mathrm{Cl}^{\prime}$ from the body fluids, following obstruction, in terms of the original total amounts of these substances in the blood plasma. These data, except the values for plasma water, are derived from the averages of the measurements from the controls and from the four animals with obstruction at the pylorus, and from the single measurements from animal no. 9 in which the obstruction was placed at the lower end of the duodenum. The estimations of the initial quantity of water in the plasma were obtained by taking plasma volume as $3.1 \times$ body weight, and water as $0.92 \times$ plasma volume. The first of these factors was derived from Utheim's (2) measurements of blood volume in rabbits by the dye method, and the second

TABLE 2

Estimations of loss of water, fixed base, and chloride, following pyloric and duodenal obstruction in terms of original blood plasma content

\begin{tabular}{|c|c|c|}
\hline Experimental procedure & $\begin{array}{l}\text { Pylorus } \\
\text { obstructed }\end{array}$ & $\begin{array}{l}\text { Duodenum } \\
\text { obstructed }\end{array}$ \\
\hline & $c c$. & $c c$. \\
\hline Water lost. . & 203 & 235 \\
\hline Initial plasma $\mathrm{H}_{2} \mathrm{O} \ldots \ldots \ldots$ & 83 & 77 \\
\hline \multirow[t]{2}{*}{$\mathrm{H}_{2} \mathrm{O}$ lost $\div$ initial plasma $\mathrm{H}_{2} \mathrm{O} \ldots \ldots \ldots \ldots \ldots \ldots \ldots \ldots \ldots \ldots \ldots \ldots \ldots$} & 2.4 & 3.1 \\
\hline & $c c .0 .1 \mathrm{~N}$ & cc. $0.1 \mathrm{~N}$ \\
\hline Fixed base lost. & 270 & 539 \\
\hline Initial plasma $\mathrm{B}^{*}$. & 140 & 130 \\
\hline 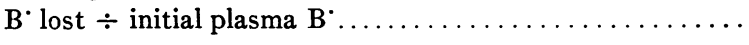 & 1.9 & 4.1 \\
\hline Chloride lost. . . . . . & 309 & 265 \\
\hline Initial plasma $\mathrm{Cl}^{\prime}$. & 85 & 79 \\
\hline $\mathrm{Cl}^{\prime}$ lost $\div$ initial plasma $\mathrm{Cl}^{\prime} \ldots \ldots, \ldots \ldots \ldots \ldots \ldots \ldots \ldots \ldots \ldots \ldots$ & 3.6 & 3.4 \\
\hline
\end{tabular}

was directly determined in a plasma sample from one of the controls The values for the total initial plasma content of fixed base and of chloride were computed from the estimated water volume and the average concentration of $\mathrm{B}^{\cdot}$ and of $\mathrm{Cl}^{\prime}$ found in the controls (see table 1). The extent of loss of each substance was estimated, as indicated in figure 1, by subtracting the average of the measurements from the controls from the average of the measurements obtained following osbtruction. Obviously these data are roughly derived. They nevertheless serve to illustrate the quite startling rapidity of the losses of these three important body fluid constituents into the stomach by way of the blood plasma. As may be seen in the table, more than 
twice the initial plasma content of water enters the stomach during the survival period following obstruction at the pylorus. Measurements of plasma volume in the presence of circumstances producing severe dehydration which have been reported (3) place the maximal reduction of volume at from 30 to 40 per cent. Depletion of plasma water to this extent would here represent only a fraction of the total loss of water.

Since a large reduction of $\left(\mathrm{Cl}^{\prime}\right)$ is seen in the plasma (table 1) it is not surprising that the loss of chloride ion into the stomach is found to be much larger than the loss of water, being 3.6 times the initial plasma content. As there is also a considerable reduction of (B') in the plasma, a larger loss of fixed base than of water might be expected. The average estimated base loss into the stomach following pyloric obstruction is, however, less than the water loss. This discrepancy may very possibly be due to an additional loss of base secreted with relatively little water into the duodenum below the obstruction. The values for loss of water and of base obtained for animal no. 9 with obstruction at the lower end of the duodenum, excellently suit this surmise. It should be pointed out, however, that the above inferences based on concentrations observed in the plasma are not necessarily reliable since the chief source of these substances is not the blood plasma but the body fluids behind it.

As recorded in table 1, the survival period of these animals is short, being in average about 30 hours. Dogs live after this operation from 2 to 4 days. It has been thoroughly shown by Hartwell and Hoguet (4) and more recently by Haden and Orr (5) that dogs, after high intestinal obstruction, may be kept alive for a much longer period ( 2 to 3 weeks) if given repeated injections of physiological salt solution. The effect of administering $\mathrm{NaCl}$ solution to rabbits following pyloric obstruction was observed in animals nos. 10 and 11. In the case of no. 10 the first injection was not given until the morning following the day of operation. This animal became moribund at the end of 48 hours. Measurements obtained from the stomach contents and from a small amount of urine voided, given in table 3 , indicate loss of all of the administered $\mathrm{H}_{2} \mathrm{O}, \mathrm{B}^{\cdot}$ and $\mathrm{Cl}^{\prime}$, with additional losses corresponding roughly to those found in the untreated animals. The degree of distension of the stomach in order to contain $\frac{3}{4}$ of a 
litre of fluid was extraordinary. The other animal (no. 11) was given a first injection a short time after operation and two injections were given the next day. Whether it was because of the more suitable amounts and intervals of administration of salt solution can not be said, but this animal when sacrificed at the end of 42 hours was alert and vigorous. The measurements obtained (table 3 ) demonstrate a much less rapid dehydration than occurred in animal no. 10 and a positive balance from the injected $\mathrm{H}_{2} \mathrm{O}, \mathrm{B}^{\cdot}$ and $\mathrm{Cl}^{\prime}$. This, it may be incidentally noted, caused an actual increase of plasma (B') above its normal value which produced, in the presence of a usual

TABLE 3

Estimations of balance for water, fixed base, and chloride, in animals given injections of $\mathrm{NaCl}$ solution following obstruction of the pylorus

\begin{tabular}{|c|c|c|c|c|c|c|}
\hline & \multicolumn{3}{|c|}{ Animal no. 10} & \multicolumn{3}{|c|}{ Animal no. 11} \\
\hline & $\mathrm{H}_{z} \mathrm{O}$ & B. & $\mathrm{Cl}^{\prime}$ & $\mathrm{H}_{2} \mathrm{O}$ & B. & $\mathrm{Cl}^{\prime}$ \\
\hline & $c c$. & $c c .0 .1 \mathrm{~N}$ & cc. $0.1 \mathrm{~N}$ & $c c$. & cc. $0.1 \mathrm{~N}$ & cc. $0.1 \mathrm{~N}$ \\
\hline Found in stomach. & 722 & 828 & 1040 & 369 & 326 & 620 \\
\hline In stomach before obstruction* & 80 & 74 & 134 & 98 & 116 & 196 \\
\hline Lost in stomach secretions. & 642 & 754 & 906 & 271 & 210 & 424 \\
\hline Lost in urine. & 45 & 70 & 5 & 70 & 110 & 9 \\
\hline Total lost. . & 687 & 824 & 911 & 341 & 320 & 433 \\
\hline Given as $\mathrm{NaCl}$ solution. & 400 & 620 & 620 & 420 & 652 & 652 \\
\hline Balance. & -287 & -202 & -291 & +79 & +332 & +219 \\
\hline
\end{tabular}

* For this factor average of measurements from controls is used in the case of no. 10. As no. 11 was a very large animal, the data from no. 2, the largest of the controls, was taken.

$\left(\mathrm{Cl}^{\prime}\right)$, an increase of $\left(\mathrm{HCO}_{3}{ }^{\prime}\right)$. These data suggest that, although the progress of dehydration is extremely rapid in rabbits following pyloric obstruction, frequent injections of appropriate amounts of salt solution would considerably prolong the survival period, at least until further distension of the stomach became impossible.

Haden and Orr $(5,6)$ have advanced the hypothesis that the benefit from injections of $\mathrm{NaCl}$ solutions following pyloric or upper intestinal obstruction is the result, not only of repair of dehydration, but also of a protective action exerted by chloride ion against a toxic substance assumed to be absorbed from the gastro-intestinal tract. They regard the chloride reduction in the plasma as only partially explained by 
loss in gastric secretions since they find it in dogs in the presence of little or no vomiting and in rabbits which cannot vomit. They apparently derive the inference that the decrease in plasma $\left(\mathrm{Cl}^{\prime}\right)$ is in large part due to a withdrawal into the tissues and on this basis have devised the conception of a specific protective capacity of chloride ion which is supported by injections of $\mathrm{NaCl}$ solutions. The defect in the inference that, in the absence of vomiting, no appreciable loss of $\mathrm{Cl}^{\prime}$ into the stomach can occur, is apparent from the measurements

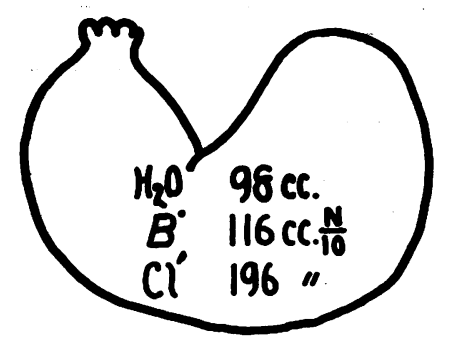

No.2, Control.

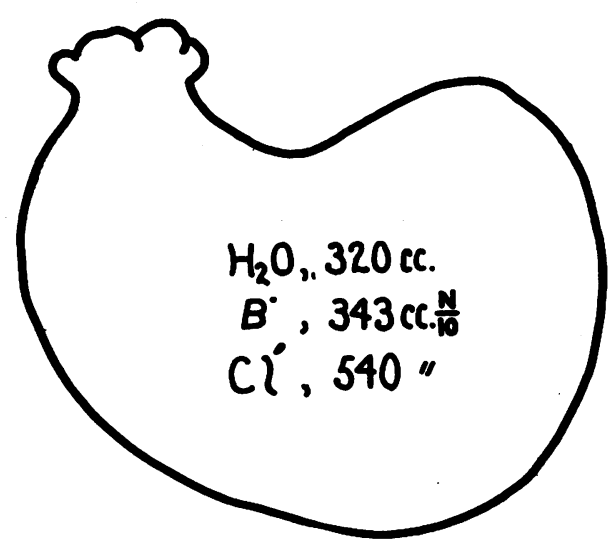

No.7, Rylorus obstructed 36 mrs.

Fig. 2. Outline Tracings of Rabitss' Stomachs (about $2 \frac{1}{2}$ Times Reduced) Illustrating Great Distension Produced by Retained Gastric Secretions Following Obstruction at the Pylorus

given above and is further illustrated by the diagrams in figure 2 . It is clearly evident from the data in table 2 that the presence of any chloride at all in the plasma proves a rapid movement of $\mathrm{Cl}^{\prime}$ in a direction quite the opposite of that surmised by these authors.

Obviously, however, the importance of the work of these investigators in thoroughly demonstrating the strikingly beneficial action of injections of $\mathrm{NaCl}$ solution in the presence of pyloric or upper intestinal obstruction is independent of conjecture offered in explanation of this effect. 
COMPOSITION OF THE FIXED BASE LOSS INTO THE STOMACH

The finding in this study which we believe is of chief interest is the large amount of fixed base entering the stomach. This loss, in proportion to the loss of $\mathrm{Cl}^{\prime}$, is larger than was observed by Gamble and Ross (1) in vomitus collected from a dog with pyloric obstruction. They found approximately $\frac{1}{2}$ of the $\mathrm{Cl}^{\prime}$ loss accompanied by $\mathrm{Na}$. Using the estimations given in table 2, it appears that in rabbits the loss of $\mathrm{B}^{\cdot}$ is more than 80 per cent of the equivalence of the $\mathrm{Cl}^{\prime}$ loss. ${ }^{1}$ We were at pains to demonstrate that, as might be expected, since the fixed base loss is derived from the blood plasma, it is composed almost entirely of $\mathrm{Na}^{\circ}$. As may be seen in table 4, there was no

TABLE 4

Composition of total fixed base in gastric contents

\begin{tabular}{|c|c|c|c|c|c|c|}
\hline Experimental procedure & $\begin{array}{l}\text { Animal } \\
\text { number }\end{array}$ & $\begin{array}{c}\text { Total } \\
\text { base }\end{array}$ & $\mathrm{Ca} \cdot$ & Mg** & $\mathbf{K}$ & $\mathrm{Na} \cdot *$ \\
\hline \multirow{3}{*}{ Control. } & & cc. $0.1 \mathrm{~N}$ & cc. $0.1 \mathrm{~N}$ & cc. $0.1 \mathrm{~N}$ & cc. $0.1 \mathrm{~N}$ & cc. $0.1 \mathrm{~N}$ \\
\hline & 1 & 68 & 3 & 4 & 20 & 41 \\
\hline & 2 & 98 & 7 & 10 & 23 & 58 \\
\hline \multirow{2}{*}{ Pylorus obstruction. } & 5 & 376 & 9 & 11 & 28 & 328 \\
\hline & 6 & 388 & 10 & 7 & 17 & 354 \\
\hline Duodenal obstruction ............ & 9 & 613 & 10 & 11 & 100 & 492 \\
\hline
\end{tabular}

* Values for $\mathrm{Na}^{*}$ obtained by subtracting the sum of those for $\mathrm{K} \cdot \mathrm{Ca}{ }^{*}$ and $\mathrm{Mg}^{*}$ from the total fixed base measurement.

appreciable increase in the amounts of $\mathrm{Ca} \cdot{ }^{-}, \mathrm{Mg}^{*}$ or $\mathrm{K} \cdot$ found in the stomach contents following pyloric obstruction. After duodenal obstruction a considerable increase of $\mathrm{K}^{\cdot}$ was measured, but here also the chief loss is of $\mathrm{Na}$. Obviously, owing to the unusual circumstances present, it is not permissible to infer from these data that $\mathrm{Na} \cdot$ is regularly a large factor in the construction and function of gastric secretions. That this may be the case is, however, suggested by the fact that $\mathrm{Na}^{\circ}$ was found to be the chief base in the stomach contents from the controls. Were the base here entirely food base, $\mathrm{K}^{\cdot}$ should be present in largest amount.

${ }^{1}$ Besides $\mathrm{Cl}^{\prime}$ a small additional inorganic acid factor in the stomach contents is indicated by the measurements of $\mathrm{HPO}_{4}$ " given at the foot of table 1 . 
MEASUREMENTS OF $\mathrm{H}_{2} \mathrm{O}, \mathrm{B}^{\cdot}$ aND $\mathrm{Cl}^{\prime}$ IN MUSCLE AND SKIN

It is evident from the data in table 2, that during the survival period following pyloric obstruction, plasma $\mathrm{H}_{2} \mathrm{O}, \mathrm{B}^{\cdot}$ and $\mathrm{Cl}^{\prime}$ are several times replaced. Maintenance of normal volume and composition will thus obviously demand a rapid movement of repair material from sources behind the plasma. It is desired here to compare briefly the probable extent of availability of these three chief components of the plasma. The loss of water as estimated in table 2, although more than twice the initial plasma volume, is in terms of the total water content of the body relatively small. Taking body water as $0.70 \times$ body weight, the loss of water into the stomachs of the rabbits with obstruction at the pyloris may be estimated as 10 per cent of the initial body water. A certain additional loss must occur by way of the lungs and skin. On the other hand there is probably replacement of water to a considerable extent from oxidation of body fat, glycogen and protein. The conjecture is thus permissible that the extra-vascular water in the body can supply replacement of a relatively very large loss from the plasma without severely depleting the tissues. Obviously, however, the plasma cannot be reconstituted from water alone. Osmotic pressure factors will prevent a restoration of volume unless ionic content can also be rebuilt. Chloride ion and fixed base of the kind required in the plasma $\left(\mathrm{Na}^{\circ}\right)$, are at hand to a very much less extent than water. Neither $\mathrm{Na}^{\cdot}$ nor $\mathrm{Cl}^{\prime}$, the chief acid factor in plasma, are contained to appreciable extent in the largest compartment of extravascular water-the skeletal musculature. Presumaby an important source from which these repair units may be derived is the skin where they are much more abundantly present, probably to a large extent in the interstitial fluid.

By way of partially illustrating the much smaller availability of $\mathrm{Na}^{\circ}$ and $\mathrm{Cl}^{\prime}$ than of $\mathrm{H}_{2} \mathrm{O}$, the few measurements contained in table 5 are presented. These were obtained from samples of muscle and skin taken from one of the controls, no. 4, and from rabbit 8, 27 hours after ligature of the pylorus. The very slight extent to which muscle tissue contains the electrolytes required for plasma repair is shown by the measurements from the control animal. The determinations from the skin samples show much larger concentrations of $\mathrm{Na}^{\circ}$ and $\mathrm{Cl}^{\prime}$ and 
extensive contributions therefrom. It is of interest to note that base which will only slightly serve in reconstituting the plasma fixed base is not appreciably withdrawn; as shown, in the case of $\mathrm{K}^{\cdot}$ and $\mathrm{Mg}^{*}$, by an actual rise in the amounts found per 100 gram of skin accompanying the moderate loss of water. Haden and Orr (5) have shown some benefit from injection of hypertonic solutions of $\mathrm{NaCl}$ following pyloric obstruction. This finding they regard as demonstrating the the specific protective action of chloride ion. It is, however, consistent with the excess of availability of water over that of electrolytes here pointed out.

TABLE 5

Data from analyses of muscle and skin from animals no. 4 and no. 8 , demonstrating differences in extent of possible availability of flasma electrolytes from tissues

\begin{tabular}{|c|c|c|c|c|}
\hline \multirow{2}{*}{ Values per 100 grams } & \multicolumn{2}{|c|}{ Muscle } & \multicolumn{2}{|c|}{ Skin } \\
\hline & Control & $\begin{array}{c}\text { Pylorus } \\
\text { obstruction }\end{array}$ & Control & $\begin{array}{c}\text { Pylorus } \\
\text { obstruction }\end{array}$ \\
\hline Water, grams, ......... & 76.4 & 72.7 & 64.7 & 58.8 \\
\hline $\mathrm{Cl}^{\prime}$, cc. 0.1 N., .......... & 8.4 & 6.8 & 63.0 & 36.0 \\
\hline Total fixed base, cc. $0.1 \mathrm{~N} . \ldots$. & 121.0 & & 119.0 & 103.0 \\
\hline $\mathrm{Ca}{ }^{*}$ cc. $0.1 \mathrm{~N} \ldots \ldots \ldots \ldots \ldots$ & 2.4 & & 6.5 & 6.3 \\
\hline $\mathrm{Mg}{ }^{\prime} \mathrm{cc} .0 .1 \mathrm{~N} \ldots \ldots \ldots$ & 12.3 & & 6.4 & 7.2 \\
\hline $\mathrm{K}^{\circ}$ cc. $0.1 \mathrm{~N} . \ldots \ldots$ & 103.0 & & 34.4 & 36.6 \\
\hline $\mathrm{Na}^{*}$ cc. $0.1 \mathrm{~N} . .$. & 3.3 & & 71.3 & 52.9 \\
\hline
\end{tabular}

* Values for $\mathrm{Na}^{*}$ obtained by subtracting the sum of those for $\mathrm{Ca}{ }^{*}, \mathrm{Mg}^{*}$, and $\mathrm{K}^{*}$ from the total fixed base measurement.

\section{CHANGES IN PLASMA STRUCTURE FOLLOWING PYLORIC OBSTRUCTION}

The few data in table 5 indicate that the losses from the blood plasma can produce but little alteration in muscle fluid composition. If it is the case that intra-cellular fluid elsewhere contains very little of the material required for plasma repair, cell composition in the vitally important tissues will be little affected by plasma depletions. It would thus appear that, if these losses from the plasma lead to the death of the organism, this event must be referable chiefly to a failure of the function of the blood from disintegration of its chemical structure due to lack of replacement material, rather than to coincident changes in the composition of the tissue cells. That the decline of 
vital functions, in the presence of dehydration, may be attributed to impairment of circulation due to physical changes in the blood has been well argued by Marriott and his co-workers (7).

Regrettably, very few measurements of blood plasma values were obtained from the operated rabbits. These will, however, serve to

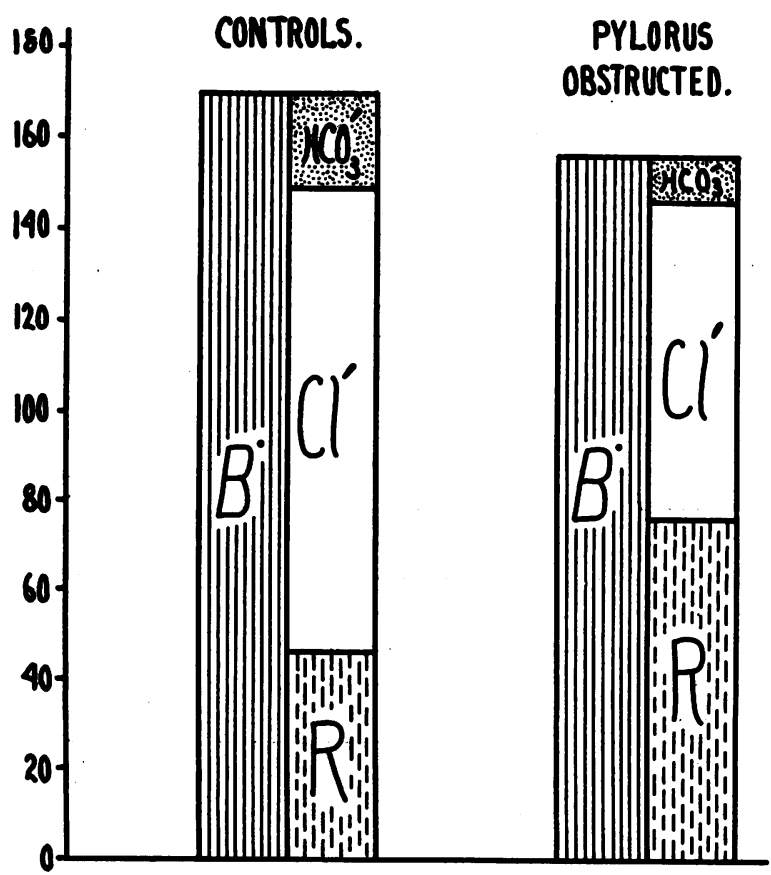

Fig. 3. Illustrating Changes in Chief Factors of Acid-base Structure of Blood Plasma Following Obstruction of the Pylorus

Diagrams constructed from averages of measurements of $\mathrm{B}^{\circ}, \mathrm{Cl}^{\prime}$, and $\mathrm{HCO}_{3}{ }^{\prime}$ (as cubic centimeters $0.1 \mathrm{~N}$ per $100 \mathrm{cc}$. of plasma) given in table $1 . R$ represents the sum of the unmeasured acid factors, i.e., $\mathrm{HPO}_{4}{ }^{\prime \prime}, \mathrm{SO}_{4}{ }^{\prime \prime}$, organic acids, and protein.

show the character of the changes in the ionic composition of the plasma which may result from the losses into the stomach. The averages of the measurements of $\left(\mathrm{B}^{\circ}\right),\left(\mathrm{Cl}^{\prime}\right)$ and $\left(\mathrm{HCO}_{3}{ }^{\prime}\right)$ from the controls and of those from two of the animals after obstructing the pylorus, given in table 1, have been used in constructing the diagrams in figure 3. The measurements show, following obstruction, a reduction of all 
three of the factors measured. The large decrease in $\left(\mathrm{HCO}_{3}{ }^{\prime}\right)$ is perhaps surprising since in dogs and in man an alkalosis of some degree is nearly regularly found in the presence of obstruction at the pylorus. Gamble and Ross (1) have, however, pointed out that the increase of $\left(\mathrm{HCO}_{3}{ }^{\prime}\right)$ which the reduction of $\left(\mathrm{Cl}^{\prime}\right)$ tends to produce is greatly limited by decrease of $\left(\mathrm{B}^{*}\right)$ and by increase in some acid factor or factors as shown by increase of the sum of the individually unmeasured acid values designated as $R$ in figure 3 . The data in this paper show a much greater loss of $\mathrm{Na}^{\circ}$ in proportion to $\mathrm{Cl}^{\prime}$ into the stomach than occurs in the dog, at least according to the measurements from the single experiment reported, and also an initially larger value for $\mathbf{R}$ in the plasma. As the diagrams indicate, the tendency of the loss of $\left(\mathrm{Cl}^{\prime}\right)$ to produce an increase of $\left(\mathrm{HCO}_{3}{ }^{\prime}\right)$ was in these rabbits more than offset by reduction of $\left(B^{*}\right)$ and increase in $R$. As causes for this increase of $R$ may be suggested an increased concentration of protein resulting from loss of plasma water and retention of other normal components of this fraction of total plasma acid due to the nearly anuric condition of these animals. It is not desired to suggest that rabbits following obstruction of the pylorus regularly die of an acidosis resulting from bicarbonate reduction although it is permissible to suppose that they occasionally may. The large reduction of bicarbonate in the plasma should, we believe, be regarded simply as one among many physical changes which together tend to impair the function of the blood.

\section{SUMMARY}

Following experimental obstruction of the pylorus in rabbits and during a short survival period, usually less than 30 hours, large amounts of water, fixed base, and chloride ion enter the stomach. These losses are, in extent, several times the initial total plasma content of $\mathrm{H}_{2} \mathrm{O}, \mathrm{B}^{\circ}$, and $\mathrm{Cl}^{\prime}$. Although rapid replacement occurs, correct plasma composition cannot be sustained. A much lower availability of the required electrolytes $\left(\mathrm{Na}^{\circ}\right.$ and $\left.\mathrm{Cl}^{\prime}\right)$ than of water, from elsewhere in the body fluids, is the limiting factor in plasma repair. The changes in the plasma which were observed in this study consist in a considerable reduction of $\left(\mathrm{B}^{\circ}\right)$ and a larger recession of $\left(\mathrm{Cl}^{\prime}\right)$ which, however, is more than offset by increase of an undetermined acid 
factor, or factors, with the result that plasma bicarbonate is greatly reduced. Plasma composition may be approximately repaired and the survival period considerably prolonged by repeated intraperitoneal (or subcutaneous) injections of $\mathrm{NaCl}$ solution. The losses from the plasma, however, continue and, in the rabbit, rapidly produce an enormous distention of the stomach.

The significance of a loss of body fluid is inadequately described by the term dehydration. Impairment of function following this event is referable not only to the loss of water, but also, and in larger degree, to the accompanying loss of particular electrolytes. An essential requirement in the treament of dehydration is replacement of these ionic factors of body fluid structure.

The entrance into the stomach of a large amount of fixed base, more than three-fourths the equivalence of the chloride ion loss, constitutes a finding which is probably of important significance as regards the construction and function of gastric juice.

\section{Methods used in obtaining measurements}

The gastric contents from the operated animals, which was largely fluid, was, after weighing, made up to a convenient volume in a stoppered graduated cylinder. As quickly as possible after thorough mixing an aliquot was taken and chloride determined in a sample from the supernatant portion. The remainder was dried on the steam bath, weighed, ground in a morter, and a 2 gram portion nearly completely ashed by the Stolte method. The partially ashed material was extracted with four $10 \mathrm{cc}$. portions of $0.5 \mathrm{~N} \mathrm{HCl}$ and, filtering through a small No. 40 Whatman paper, made up to a volume of $100 \mathrm{cc}$. Fixed base was determined in an aliquot from this extract. In the case of the controls the portion used for the chloride determination was measured by weighing, digested with about 10 times its weight of distilled water on the steam bath, and then made up to volume. The blood samples were obtained by cardiac puncture and the values given were determined in the serum. The muscle and skin samples were taken directly following death of the animals. Chloride was directly determined in 2 to 3 gram samples and fixed base in 15 to 20 gram samples ashed by the Stolte method and extracted with $0.5 \mathrm{~N} \mathrm{HCl}$. The measurements of potassium, calcium, magnesium, and phosphorus given were also determined in the extracts of ashed material.

References to descriptions of chemical methods used are as follows: Total Fixed Base, Fiske (8); Chloride, Fiske (to be published); Bicarbonate, Van Slyke (9); Potassium and Calcium, Tisdall and Kramer (10); Magnesium, Briggs (11); Phosphorus, Briggs (12). 


\section{BIBLIOGRAPHY}

1. Gamble, J. L., and Ross, S. G.: Jour. Clin. Invest., 1925, i, 403.

2. Utheim, K.: Amer. Jour. Dis. Child., 1920, xx, 366.

3. Cited from Marriott, W. McK.: Physiol. Rev., 1923, iii, 275.

4. Hartwell, J. A., and Hoguet, J. P.: Jour. Amer. Med. Ass., 1912, lix, 82.

5. Haden, R. L., and Orr. T. G.: Jour. Exper. Med., 1923, xxviii, 55.

6. Haden, R. L., and Orr, T. G.: Jour. Amer. Med. Ass., 1924, lruxii, 1515.

7. Marriott, W. McK.: Harvey Lectures, 1920.

8. Fiske, C. H.: Jour. Biol. Chem., 1922, li, 55.

9. Van Slyke, D. D., Jour. Biol. Chem., 1917, $\operatorname{xxx}, 347$.

10. Tisdall, F. F., and Kramer, B.: Jour. Biol. Chem., 1921, xlviii, 1.

11. Briggs, A. P.: Jour. Biol. Chem., 1922, lii, 349.

12. Briggs, A. P.: Jour. Biol. Chem., 1922, liii, 13. 